\title{
Stochastic load profile construction for the multi-tier framework for household electricity access using off-grid DC appliances
}

\author{
Nishant Narayan (D) - Zian Qin . \\ Jelena Popovic-Gerber · Jan-Carel Diehl • \\ Pavol Bauer · Miroslav Zeman
}

Received: 10 May 2018 / Accepted: 13 August 2018/Published online: 5 November 2018

(C) The Author(s) 2018, corrected publication 2018

\begin{abstract}
To improve access to electricity, decentralized, solar-based off-grid solutions like Solar Home Systems (SHSs) and rural micro-grids have recently seen a prolific growth. However, electrical load profiles, usually the first step in determining the electrical sizing of off-grid energy systems, are often nonexistent or unreliable, especially when looking at the hitherto un(der)-electrified communities. This paper aims to construct load profiles at the household level for each tier of electricity access as set forth by the multi-tier framework (MTF) for measuring household electricity access. The loads comprise dedicated offgrid appliances, including the so-called super-efficient ones that are increasingly being used by SHSs, reflecting the off-grid appliance market's remarkable evolution in terms of efficiency and price. This study culminated in devising a stochastic, bottom-up load
\end{abstract}

The original version of this article was revised: Figure 5 image top right legends, the solid black line was defined "CF" and the broken blue line was described "CF" too. The figure image was updated to correct the mistake.

N. Narayan $(\bowtie) \cdot$ Z. Qin · J. Popovic-Gerber · P. Bauer . M. Zeman

Department of Electrical Sustainable Energy, Delft

University of Technology, Delft, The Netherlands

e-mail: N.S.Narayan@tudelft.nl

J.-C. Diehl

Faculty of Industrial Design Engineering, Delft University of Technology, Delft, The Netherlands profile construction methodology with sample load profiles constructed for each tier of the MTF. The methodology exhibits several advantages like scalability and adaptability for specific regions and communities based on community-specific measured or desired electricity usage data. The resulting load profiles for different tiers shed significant light on the technical design directions that current and future offgrid systems must take to satisfy the growing energy demands of the un(der)-electrified regions. Finally, a constructed load profile was also compared with a measured load profile from an SHS active in the field in Rwanda, demonstrating the usability of the methodology.

Keywords Load profile - Solar Home System . Energy demand · Multi-tier framework for electricity access · Off-grid DC appliances · Stochastic model . Rural microgrids

\section{Introduction}

In 2016, the 17 Sustainable Development Goals (SDGs) of the 2030 Agenda for Sustainable Development came into force (United Nations 2017). In the same year, an estimated 1.1 billion people globally lacked access to electricity (IEA 2017). It is no wonder then that the United Nations defines SDG \#7 as "Ensure access to affordable, reliable, sustainable and modern energy for all" (United Nations 2017). 


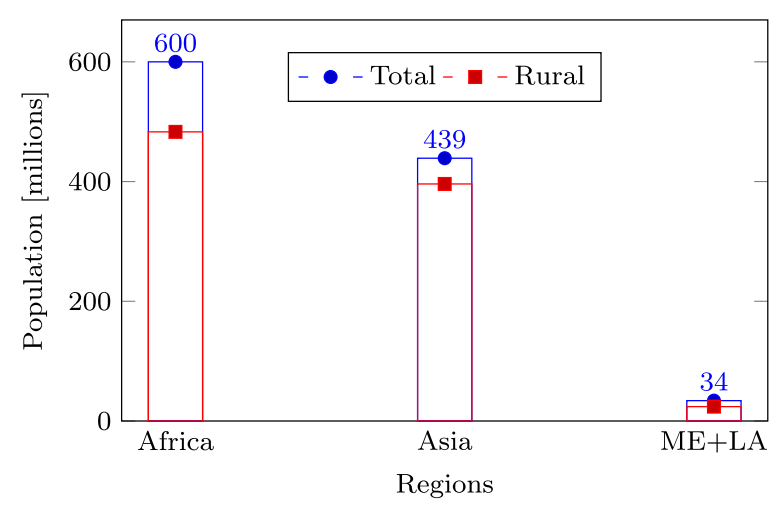

Fig. 1 Distribution of globally unelectrified population as of 2016 (data sourced from IEA 2017). ME, Middle-East; LA, Latin America

Figure 1 shows the distribution of the global population without electricity across various regions. A large majority (nearly $85 \%$ ) of the global population without electricity access lives in the rural areas.

Hope in off-grid electrification

For various reasons, grid extension efforts in the electricity-deficient areas have been slower than desired, and in some cases, grid extension may not be the best way forward at all (Palit and Bandyopadhyay 2016; Narayan et al. 2017). It has also been estimated that by 2030, decentralised systems will offer the most costeffective means of electricity access for over $70 \%$ of those gaining electricity access in the rural areas (IEA 2017). In particular, solar-based off-grid rural electrification seems to complement as well as compensate for the grid extension efforts in most of the underelectrified regions. Solar Home Systems (SHSs) and solar-based mini-grids are the perfect examples. An SHS is usually defined as a solar photovoltaic (PV)based generator rated $11-20 \mathrm{Wp}$ (entry-level SHS) to $>100 \mathrm{Wp}$ (high-power SHS) and a suitable battery storage (Global Off-Grid Lighting Association 2018). An argument in favor of the solar-based off-grid solutions is that most of the unelectrified regions belong to the sunnier latitude belts. Additionally, the technology costs of the so-called exponential technologies like solar PV, LED, and batteries have been declining. Accordingly, 4.14 million solar-based products were sold globally in the second half of 2017, bringing the number of people currently living in households using solar energy source to 72.3 million (Global Off-Grid Lighting Association 2018).
Multi-tier framework for household electricity access

In the past, governments have often defined electricity access as a connection to an electrical grid, whether or not that connection is reliable. Additionally, large sections of the people (e.g., a whole village) have also been called electrified if a small percentage of the households is electrified (Tenenbaum et al. 2014). Until the previous decade, electricity access was largely looked at as a have or have-not condition. However, such oversimplification is a dangerously narrow view of understanding and acting towards the electricity access problem. Such binary metrics were therefore considered insufficient, and a multi-tier framework (MTF) was proposed by Bhatia and Angelou (2015), which captures the multi-dimensional nature of electricity access. Table 1 captures the MTF as described in Bhatia and Angelou (2015).

The central idea behind the MTF is to view electrification in terms of the quality and quantity of the energy services supplied to the user. The underlying premise is that different energy service attributes, as listed in Table 1, define the electricity usage that satisfies the various human needs. Human needs broadly encompass the following categories: (a) lighting, (b) entertainment and communication, (c) food preservation, (d) mechanical loads and labor-saving, (e) cooking and water heating, (f) space cooling and heating (Tenenbaum et al. 2014). The household-level energy use is bound to be increasing with time as more households rise out of (energy) poverty (Wolfram et al. 2012). Moving up the tiers makes more and better quality energy services available that could satisfy more of these human needs. The notion of this tier-based framework is independent of the type of technology that enables the electrification.

\section{Off-grid appliances}

Since the dawn of electricity, the electricity appliance market has always been under a constant state of evolution. However, until recently, most major advents of electrical appliances and devices in the developing world have largely been on the heels of their success in the developed world. Examples include mobile phones and LED lights. This trend has now been broken, and a number of dedicated, so-called superefficient off-grid appliances are being designed specifically for the off-grid markets (Phadke et al. 2015; 
Table 1 Multi-tier matrix for measuring access to household electricity supply

\begin{tabular}{|c|c|c|c|c|c|}
\hline & Tier 1 & Tier 2 & Tier 3 & Tier 4 & Tier 5 \\
\hline $\begin{array}{l}\text { Peak power rating } \\
\text { and energy }\end{array}$ & $>12 \mathrm{Wh},>3 \mathrm{~W}$ & $>200 \mathrm{Wh},>50 \mathrm{~W}$ & $>1 \mathrm{kWh},>200 \mathrm{~W}$ & $>3.4 \mathrm{kWh},>800 \mathrm{~W}$ & $>8.2 \mathrm{kWh},>2 \mathrm{~kW}$ \\
\hline Availability (h/day) & $>4$ & $>4$ & $>8$ & $>16$ & $>23$ \\
\hline $\begin{array}{l}\text { Availability } \\
\text { (h/evening) }\end{array}$ & $>1$ & $>2$ & $>3$ & $>4$ & $>4$ \\
\hline Reliability & - & - & - & $\begin{array}{l}<14 \text { disruptions per week } \\
\text { per week }\end{array}$ & $<3$ disruptions \\
\hline Quality & - & - & - & \multicolumn{2}{|c|}{$\begin{array}{l}\text { Voltage problems do not affect the use } \\
\text { of desired appliances }\end{array}$} \\
\hline Affordability & - & - & - & \multicolumn{2}{|c|}{$\begin{array}{l}\text { Cost of } 365 \mathrm{kWh} / \text { year }<5 \% \text { of } \\
\text { household income }\end{array}$} \\
\hline Legality & - & - & - & \multicolumn{2}{|c|}{$\begin{array}{l}\text { Bill is paid to the utility or authorized } \\
\text { representative }\end{array}$} \\
\hline Health and safety & - & - & - & \multicolumn{2}{|c|}{$\begin{array}{l}\text { Absence of past accidents and high risk } \\
\text { perception in the future }\end{array}$} \\
\hline
\end{tabular}

Sourced from Bhatia and Angelou (2015)

Global LEAP 2016a). Examples include electric fans, TVs (Park and Phadke 2017), and refrigerators, all of which can work on DC as well as consume just a fraction of the energy costs of the traditional, mainstream counterparts. Moreover, high-quality off-grid products tailor-made for the low-income markets combined with innovative business models and falling component costs have enabled the rapid market growth.

Envisioning universal electricity access by 2030 would require the support of off-grid, stand-alone systems as well. The use of super-efficient appliances will greatly help in this regard, as seen in Fig. 2. The higher cost of bundling super-efficient appliances is more than compensated by the lower cost of the PV and battery due to reduced system size needed to deliver the same energy services. In this particular example, an average annual cost reduction of $32 \%$ can be achieved (IEA 2017). In general, coupling super-efficient devices has been seen as a means to delivering the same, if not better energy services at lower costs, while also increasing the momentum of the energy access efforts (REN21 2017).

Moreover, many of these appliances can be used for their productive use of energy, i.e., using the appliances for improving the productivity and supplementing income (GIZ 2016). Productive use of energy (PUE) is different from the usual, consumptive use of energy, in that the productive use is labor-saving and supplements the income generation capabilities of the user. Some examples are in small enterprises (sewing machines, power drills) and farming (solar pumps). The biggest advantage of PUE comes in the form of benefits towards both poverty reduction as well as stability and viability of energy supply, due to increased ability to pay for the energy services,

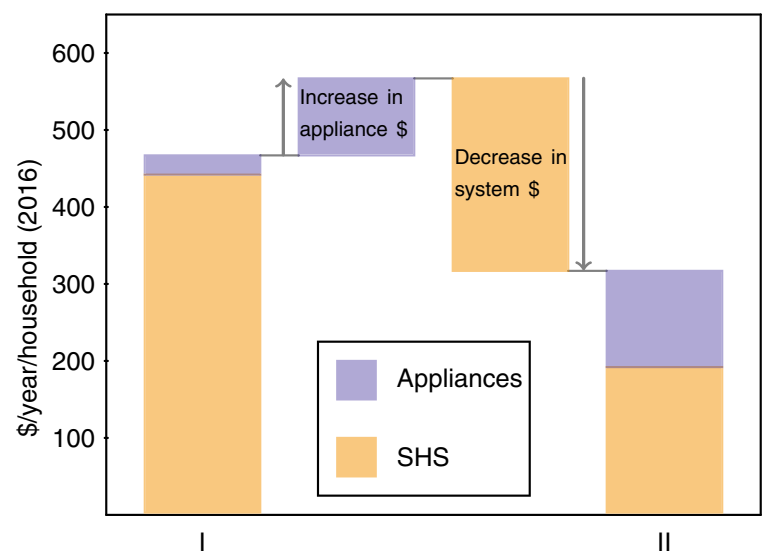

Fig. 2 Impact of using super-efficient appliances in overall system costs. Assuming universal electricity access by 2030, annual average cost per household powered by SHS and using four lightbulbs, a television, a fan, a mobile phone charger, and a refrigerator. I: SHS with standard appliances; II: SHS with super-efficient appliances. Use of super-efficient appliances leads to an overall decrease in total costs. Adapted from IEA (2017) 
and less reliance on subsidies (Kooijman-van Dijk 2008). However, not all dedicated off-grid appliances available today can be classified in the super-efficient category. For instance, washing machines and air coolers still have a long way to go in terms of efficiency improvements.

It is interesting to note that super-efficient appliances are also being promoted from the policy side by governments and are not necessarily limited to the offgrid sector. For example, by providing production subsidies to appliance manufacturers, the Super Efficient Equipment Program (SEEP) aims at reducing energy consumption in Indian households (Troja 2016). International collaborative programs like CLASP are also working towards improving energy efficient appliances.

Importance of load profiles

A load profile can be defined as the power demand of an energy system mapped over time. A load profile not only captures the energy demand of the user but also serves as a vital input to the electrical system design. Especially in the case of off-grid power systems like the SHSs, reliable apriori knowledge of the load profile is extremely helpful in the electrical sizing the system (i.e., deciding the PV rating and the battery capacity).

In fact, load profile, even if coarsely estimated, is almost always the starting point in an off-grid, standalone PV system design (Smets et al. 2016). Load profiles can have a profound impact on the performance as well as design decisions in off-grid systems (Treado 2015). A better knowledge of load profile makes for a more optimal off-grid electrical system design. Conversely, the lack of an appropriate load profile leads to either oversizing or undersizing the system, thereby causing an unhealthy trade-off between system costs and power availability (Heeten et al. 2017).

An over-utilization will result in frequently empty batteries and loss-of-load events. Particularly in the context of first-time SHS users, this may result in loss of faith and trust in solar-based electrification, as was experienced during the fieldwork done in rural Cambodia related to the work reported in Heeten et al. (2017). On the other hand, underutilization would have a detrimental financial impact. This is because the user would pay more for effectively utilizing only a fraction of the power generation potential of the system. In terms of the Levelized Cost of Electricity (LCOE), a grossly underutilized system would result in a high LCOE. In a market segment where purchase power, cost price, and profit margins are sensitive parameters, a high LCOE is definitely unattractive, whether or not there are subsidies in play.

Need for load profile construction

The following points necessitate the requirement for load profile construction.

- Difficult to estimate It is tough to estimate the energy consumption behavior in off-grid communities if the electricity access has hitherto been limited.

- Starting point The load profile is the starting point in off-grid system design. In the absence of existing load profiles, as is the case with most offgrid locations, reliable load profile construction is crucial.

- Growth enabling Load profile construction for not just the present but an estimated future usage would benefit the off-grid system designers to enable the growth of the energy consumption in their off-grid systems.

\section{Contributions}

For the goal of achieving an optimal SHS design, the work described in this paper endeavors to construct load profiles by mapping the energy usage for various tiers of electricity access. While multiple studies in the past have discussed load profile construction (as discussed in the "Literature review" section), this paper focuses specifically on stochastic load profile construction for the various tiers of the MTF for electricity access. Following are the main contributions of this paper.

1. A fully adaptable, scalable, and bottom-up load profile construction methodology is presented, which can be customized for different regions and user groups.

2. The constructed load profiles include the latest trends in dedicated off-grid appliances for each tier of the MTF for household electricity access.

3. Off-grid appliances for productive use of energy are included while constructing the load profiles. 
4. The stochastic load profile construction model is validated through a comparison with a measured load profile from an active SHS in the field.

5. The impact of load profiles on off-grid system design is discussed.

\section{Background}

This section discusses a brief literature review on the existing load profile construction methodologies, and details the load profile parameters and the types of offgrid electrical appliances considered in this study.

\section{Literature review}

Load profile construction can be a complex task for the rural off-grid scenario. The electrical consumption of the target users is often increasing with time, as the process of electrification itself contributes to greater energy needs because of improvement in living standards (Gustavsson 2007). It is therefore important for rural off-grid initiatives to enable communities to move beyond basic lighting and phone charging (Hirmer and Guthrie 2017).

However, the complex causality of electricity access with socio-economic development significantly impacts energy modelling approaches, while most electrification impact assessments estimate a linear growth in electricity demand (Riva et al. 2018). Limited knowledge of electricity demand can negatively impact off-grid system dimensioning. Similarly, Riva et al. (2017) say that most studies do not assume a dynamic demand over the years and do not consider the evolution of the future load demand, which severely undermines long-term planning. As seen in Riva et al. (2017), 74.4\% of energy demand forecasting approaches adopted in the reported case studies consider no evolution in the energy demand.

Fortunately, the MTF for household electricity access can be instrumental in overcoming some of these problems thanks to its multi-layered approach. The tier-based electrification makes it easier to categorically cater to different tiers of energy usages. Additionally, while the jump from, say, tier 1 to tier 2 might happen quickly for certain households, it would still take much longer to reach tier 4 or 5. Using MTF as a categorical sieve for modelling energy demand and consequently designing electrical systems still makes a better case for the future than assuming a fixed demand. Moreover, use of interviews and surveys can be used additionally to complement and calibrate the load profiles based on the MTF, thereby making them more robust as well as customized to local contexts.

In the case of rural (off-grid) electrification projects, use of only interviews to model the energy demand may not be the best way forward. Currently, energy demand estimation is often carried out solely through interviews and surveys due to lack of historical data. However, research surveys for predicting electricity consumptions can be error-prone. As high as $426 \mathrm{Wh}$ /day per consumer of mean absolute error has been observed over a study of eight rural minigrids in Kenya (Blodgett et al. 2017). Hartvigsson and Ahlgren (2018) compare the load profiles in a minigrid from interviews as well as measured data. Their study concludes that purely interview-based data falls short in accurately estimating energy needs. Therefore, interviews, when used as the only tool, need not be the best indicators of actual load consumption, especially if delicate system design and sizing is going to be based on the load profiles constructed from interview data. However, a stochastic load profile construction approach can gain greatly from interview data in terms of calibration and limits.

Existing energy modelling methods have in general been investigated by Bhattacharyya and Timilsina (2010) in the context of developing economies. Econometric (macro-scale) and end-use are the two most common approaches being used, with the latter able to produce more realistic projections. Given the task of estimating household energy demand and constructing load profiles for the same, modelling end-use consumption is more suited. Swan and Ugursal (2009) also identify two main approaches in modelling user data and generating load profiles, viz., top-down and bottom-up approaches.

Top-down approaches work on aggregate data, which does not distinguish energy consumption due to individual users. Tsekouras et al. (2008) use pattern recognition and clustering methods to generate load profiles as well as for short/mid-term load forecasting. However, this is oblivious to appliance-level data. Räsänen et al. (2010) and Nuno et al. (2012) similarly use clustering-based methodologies to peruse large datasets and construct "new" load profiles based on the existing data. Sajjad et al. (2014) discuss load 
aggregation and sampling times of measured data to determine optimal sampling times and aggregation levels.

Based on the top-down approach, these models lack appliance-level data and are not specifically suitable for off-grid applications. Reliance on historical aggregate data is a drawback of these models, as they are intrinsically incapable of modelling technological advances that are discontinuous in nature (Swan and Ugursal 2009). Therefore, top-down approach is deemed inadequate to be used for modelling the energy consumption in the form of load profiles for the purpose of electrification of remote, off-grid households that are hitherto un(der)-electrified, while also taking into account the latest developments in dedicated off-grid appliances.

On the other hand, bottom-up approaches work with individual users, and often even with appliancelevel data. Bottom-up approaches can be classified as statistical methods (SMs) or engineering methods (EMs). While SMs use regression analysis or artificial neural networks to estimate end-user energy consumptions, and use historical data, EMs account for energy consumption at individual user levels on the basis of power ratings and use of equipment (Swan and Ugursal 2009). These do not necessarily rely on historical or measured data, but measured data can be used for calibration. To construct load profiles while incorporating the off-grid appliances, only the EM methods can be used. Moreover, as one goes to a smaller scale, like a household level, load profiles need to be more appliance oriented than what the topdown approaches can offer. This is because demand and supply needs to be optimally matched in planning and operation. The maximum demand and variability decreases with increasing number of appliances and users (Boait et al. 2015). Therefore, for smaller mini-grids and SHSs, the peaks are even more disruptive and the demand and supply matching even more difficult. Consequently, a good peek into the load consumption profile at the design stage is crucial. Therefore, a bottom-up approach is chosen for stochastic load profile construction in this study.

Bottom-up approach is used in Paatero and Lund (2006), which uses datasets for hundreds of Finnish urban households to construct load profile from each load behavior. Underlying loads and appliances were obtained from other studies at the time (2006). Probability factors were taken from public reports and other available data. However, this study was primarily in the urban scenario, with contemporary loads, and considering hourly mean power levels.

Mandelli et al. (2016) also discuss a bottom-up approach to construct load profiles specifically for offgrid areas. While Mandelli et al. (2016) come closest to creating a bottom-up methodology for constructing load profiles for rural off-grid systems, there are additional aspects that are considered in the study described in this paper, which will be incorporated in the methodology described in the "Methodology" section. These include (a) Special focus on dedicated, super-efficient, off-grid (DC) appliances and related trends. (b) Formulating an analytical approach to include the coincidence factor as a design parameter for stochastic load profile construction. (c) Each load per tier constrained by a maximum usage per day. (d) Use of a measured load profile from an SHS in Rwanda to compare and validate the constructed load profile. (e) Constructing daily load profiles for an entire year so as to also account for inter-day variations. The methodology could be further complemented with interviews and data monitoring for seasonal recalibration if necessary.

\section{Load profile parameters}

The important load profile parameters that this work refers to are discussed in this section. Additionally, implications of the load parameters on the off-grid energy system are also discussed.

\section{Peak and average loads}

Peak load is the maximum power value the load profile takes over the period of consideration, while the average load is the mean load power. The electrical dimensioning of the energy system must be able to support the peak load power. In SHSs, this is usually done with adequately rated power electronic converters. Information on average loads is in itself insufficient to appropriately size the systems and often error-prone (Louie and Dauenhauer 2016).

\section{Energy demand}

The energy demand is the integral of instantaneous power demand, i.e., the summation of all load consumption events during the period of consideration. 
This has implications on the amount of electrical energy the generator like PV module has to produce in the system.

$E=\int_{0}^{T} P_{L}(t) d t$

where $E$ is the total energy demand, $P_{L}(t)$ is the instantaneous load power, and $T$ is the time interval under consideration. Consequently, the mean daily energy, which is defined as the average daily energy consumption over the given year, can be obtained as follows.

$\overline{E_{\text {daily }}}=\frac{\sum_{i=1}^{365} \int_{0}^{24 h} P_{L_{i}}(t) d t}{365}$

where $\overline{E_{\text {daily }}}$ is the mean daily energy, $P_{L_{i}}(t)$ is the instantaneous load power on day $i$.

\section{Load factor}

Load factor is defined as the ratio of the average load power to the peak load power as shown in Eq. 3 . Higher the load factor, flatter the load profile, indicative of a load demand with fewer variations. On the other hand, a low load factor is indicative of high variability in the load profile.

Load factor $=\frac{P_{L, \text { Avg }}}{P_{L, \text { Peak }}}$

where $P_{L, \text { Avg }}$ and $P_{L, \text { Peak }}$ are the average and the peak power values of the load profile over a particular day.

\section{Coincidence factor}

Coincidence factor $(\mathrm{CF})$ is defined as the ratio of the peak load power in the load profile to the total rated power of all the installed appliances in the energy system, as shown in Eq. 4 (Hartvigsson and Ahlgren 2018). It is a measure of the likelihood of all the loads constituting the load profile functioning simultaneously. This can hugely impact the electrical dimensioning of the system.

$\mathrm{CF}=\frac{P_{L, \text { Peak }}}{P_{L, \text { Tot }}}$

where $P_{L, \text { Tot }}$ is the total installed load.
Types of appliances

The "Off-grid appliances" section has already introduced the so-called super-efficient appliances increasingly being produced and used in the rural, off-grid regions. Global LEAP (2015) reports a dedicated survey on off-grid appliances to investigate the applianceproducts reflecting the greatest off-grid consumer demand, as well as driving the greatest electricity access. This survey, carried out in Africa, Latin America, and South Asia, considered a total of 19 appliances for off-grid household usage. The appliances considered in the survey have been listed in Table 2 .

The table also mentions the typical power ratings and the needs that these appliances can fulfill. This survey and its results reported in Global LEAP (2015) have been taken as the base for the selection of the loads that can meet the energy needs and can help in the construction of the load profiles. These loads can now be used in constructing the load profiles for the

Table 2 List of off-grid appliances as ranked in Global LEAP (2015)

\begin{tabular}{|c|c|c|c|}
\hline S. No. & Appliance & Needs & $\begin{array}{l}\text { Typical } \\
\text { rating [W] }\end{array}$ \\
\hline 1 & LED Lighting & $\mathrm{a}$ & $1-5$ \\
\hline 2 & Mobile charging/banks & $\mathrm{b}$ & $3-20$ \\
\hline 3 & Television & $\mathrm{b}$ & $10-50$ \\
\hline 4 & Radio & $\mathrm{b}$ & $2-5$ \\
\hline 5 & Fridges & $\mathrm{c}$ & $40-400$ \\
\hline 6 & Fan & $\mathrm{f}$ & $15-100$ \\
\hline 7 & Laptop & $\mathrm{b}$ & $30-100$ \\
\hline 8 & Solar water pumps & $\mathrm{d}$ & $40-800$ \\
\hline 9 & Tablets & $\mathrm{b}$ & $12-50$ \\
\hline 10 & Rice cooker & $\mathrm{e}$ & $200-250$ \\
\hline 11 & Clothes iron & $\mathrm{d}$ & $150-2000$ \\
\hline 12 & Grinders & $\mathrm{d}$ & $750-1000$ \\
\hline 13 & Hand power tools & $\mathrm{d}$ & $100-1000$ \\
\hline 14 & Hair clippers & $\mathrm{d}$ & $15-50$ \\
\hline 15 & Small speaker systems & $\mathrm{b}$ & $5-10$ \\
\hline 16 & Rice mills & $\mathrm{d}$ & $200-500$ \\
\hline 17 & Sewing machines & $\mathrm{d}$ & $40-100$ \\
\hline 18 & Soldering iron & $\mathrm{d}$ & $20-60$ \\
\hline 19 & Tea kettles & $\mathrm{e}$ & $100-800$ \\
\hline
\end{tabular}

The "Needs" column refers to the same human needs a to f as mentioned in Section 2 
various tiers of electricity access as outlined by the MTF.

\section{Methodology}

This section details the overall methodology used for the stochastic construction of the load profiles, along with the mathematical model that forms the core of the methodology.

\section{Load classification}

Out of the 19 listed off-grid appliances listed in Table 2, a total of 16 appliances were considered in this study, with an air cooler as an additional appliance. These loads are then classified into the 5 tiers (T-1 to T-5) of household electricity access as outlined by the MTF (Table 1). Every tier is a superset of the preceding tier with more appliances.

This classification is captured in Table 3, where the considered load appliances are listed along with their power rating, quantity, and other operating constraints that are used as inputs to the mathematical model, as described in the "Model parameters" section. Table 3 assumes typical values of operational constraints to demonstrate the applicability of the described methodology. These values are expected to be customized per target region or community.

Additionally, four dedicated appliances that contribute to productive use of energy (PUE) are considered as well in tier 5, viz., hand power tools, water pump, grinder/miller, and sewing machine. Note that the so-called super-efficient off-grid appliances are considered wherever applicable. However, some highpower appliances, although DC and off-grid, are still in the process of undergoing advancements in the offgrid market, and therefore need not necessarily be "super-efficient" like the LEDs and TV. For example, washing machine and air coolers. The appliances, and their specific datasheets, wherever applicable, are mentioned in Appendix.

\section{Model parameters}

The parameters of the mathematical model used in the methodology are defined in Table 4. The model assumes that a load can be operated in an allowed usage window multiple times for finite durations, as defined by the parameters and their constraints. The values for these parameters (including boundary values where applicable) along with details of the load appliance used for constructing the load profile can be seen in Table 3. It must be noted that these input values have a bearing on the model output, and can be tailored by the system designer using the described methodology for the specific user group being catered to.

As the data resolution in this study is $1 \mathrm{~min}, f$ (refer Table 4) is a 1440 ( 1 day long) length vector in MATLAB having ones and zeroes ( $1 \mathrm{~s}$ and $0 \mathrm{~s})$ to indicate activity or inactivity of any load.

\section{Usage window}

The idea of the usage window is illustrated in Fig. 3. The concept illustration shows a usage window $(W)$ spanning $9 \mathrm{~h}$ from 09.00 to 18.00 . Two occurrences of variable duration of a load rated $150 \mathrm{~W}$ can be seen, from 11.00 to 12.00 and from 15.00 to 18.00 . Additionally, the cycle times $\left(T_{i}\right)$, number of instances $(n)$, starting times $\left(t_{i}\right)$ and power rating $(P)$ have been marked.

\section{Peak window and coincidence factor}

Peak window is that subset of the total allowed usage window that intersects with the usage window of other loads. This is an important input parameter for the model, as depending on the coincidence factor, multiple loads will operate in the peak window at the same time or around each other.

Figure 4 illustrates the concept of the peak window. The load usage window $W_{j}$ is shown for 3 different appliances $W_{1}$ to $W_{3}$, and the intersecting time duration $W_{\text {peak }}$ is shown. For tiers 4 and 5, lower powered applications like LED lighting, mobile phone charging, and radio are not considered for determining the peak window.

Using coincidence factor The concept of coincidence factor (CF) described in the "Load profile parameters" section is an important load profile parameter, which can have implications on the off-grid system design to cater to the load profile. The coincidence factor measure is used as an attribute that impacts the probability of a load occurrence in the peak window. The probability of load occurrence times $t_{i j}$ within the peak window is considered to follow a normal distribution with 


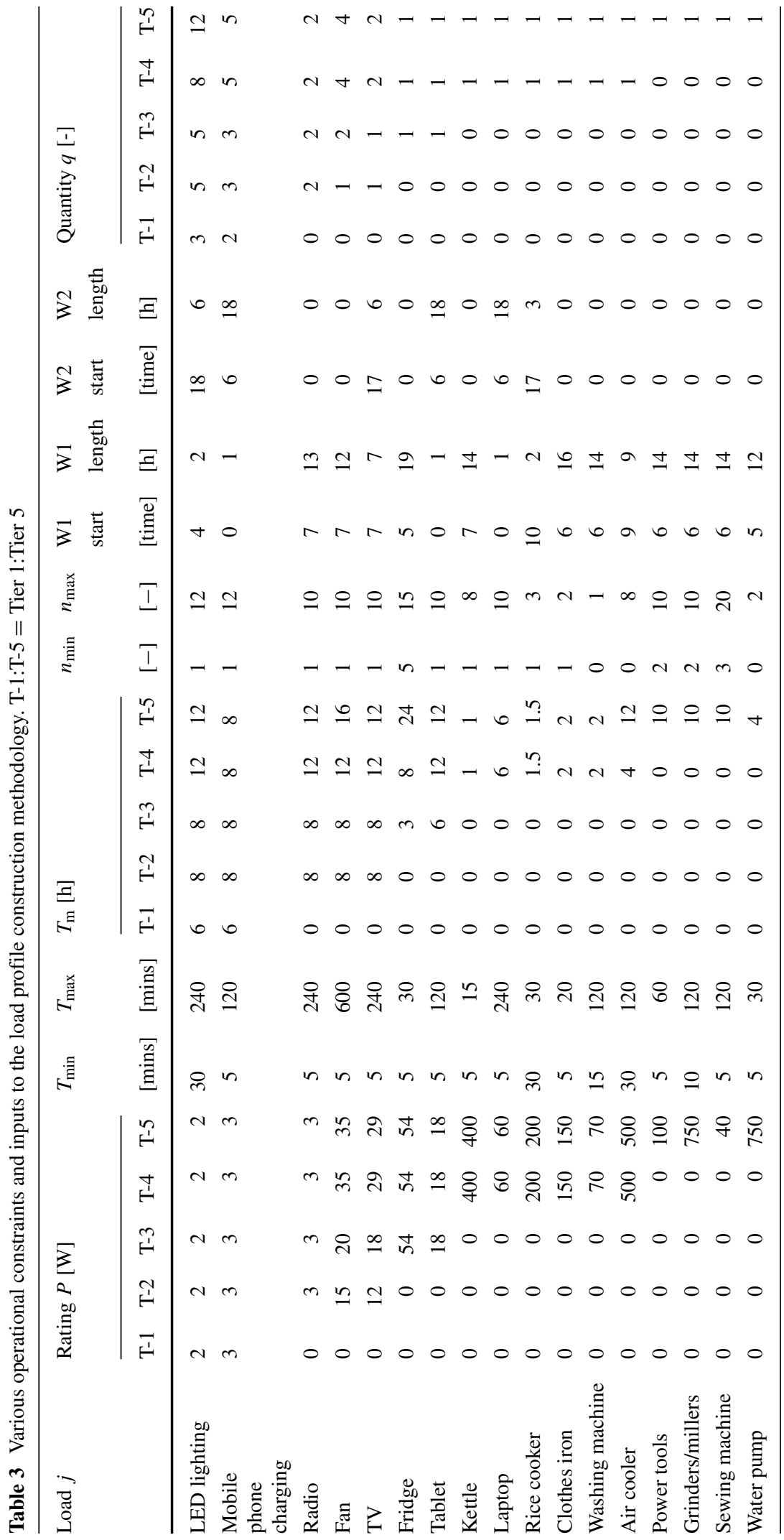


Table 4 Parameters used for stochastic load profile construction

\begin{tabular}{|c|c|c|c|}
\hline Parameter & Definition & Notation & Type \\
\hline Load type & $\begin{array}{l}\text { Type of load in use. For example, TV, LED } \\
\text { lights, etc, chosen from the LCM }\end{array}$ & $j$ & Input \\
\hline Total load type & Total load types per category & $N$ & Input \\
\hline Rated power & Rated power per load & $P$ & \\
\hline Cycle time & Duration for which a load is operational & $T$ & Generated \\
\hline Maximum usage & $\begin{array}{l}\text { Maximum number of hours a load is } \\
\text { allowed to operate during the day }\end{array}$ & $T_{\mathrm{m}}$ & Input \\
\hline Instances & $\begin{array}{l}\text { Number of times a load is operated in } \\
\text { the allowed usage window }\end{array}$ & $n$ & Generated \\
\hline Usage window & $\begin{array}{l}\text { The allowed time window within which the } \\
\text { loads are expected to be used }\end{array}$ & $W$ & Input \\
\hline Quantity of loads & The number of loads of each type & $q$ & Input \\
\hline Start time & Start time of a load instance within the usage window & $t$ & Generated \\
\hline Load occurrence & The $i$ th occurrence of a load cycle & $i$ & Generated \\
\hline Dynamic window & $\begin{array}{l}\text { Dynamic window calculated as more } \\
\text { load occurrences reduce the usage window }\end{array}$ & $W_{\text {dyn }}$ & Generated \\
\hline Functioning time & $\begin{array}{l}\text { Day long time interval showing the precise } \\
\text { time stamps when the load is active or inactive }\end{array}$ & $f$ & Output \\
\hline Peak window & $\begin{array}{l}\text { The usage window where multiple appliances } \\
\text { can potentially function simultaneously }\end{array}$ & $W_{\text {peak }}$ & Generated \\
\hline Coincidence factor & $\begin{array}{l}\text { A design input between } 0.2 \text { and } 1 \text { that denotes } \\
\text { the likelihood of appliances functioning simulatneously }\end{array}$ & $\mathrm{CF}$ & Input \\
\hline
\end{tabular}

the mean centered around the middle of the peak window. Equation 5 describes the normal probability density function with a mean $\mu$ and standard deviation $\sigma$. It is known that $99.7 \%$ of the values drawn from the normal distribution are within $3 \sigma$ distance from the mean.

$P(x)=\frac{1}{\sigma \sqrt{2 \pi}} e^{-(x-\mu)^{2} / 2 \sigma^{2}}$

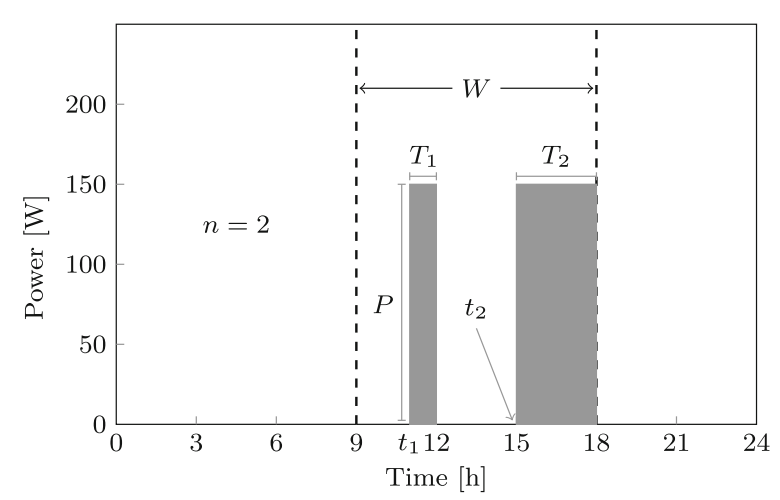

Fig. 3 Concept illustration of load usage window $(W)$ and load occurrence during the day
Figure 5 illustrates the normal probability distribution of load occurrence being superimposed on the peak window. A high coincidence factor would imply a much narrower distribution compared to a lower coincidence factor. Minimum coincidence factor gives rise to a normal distribution that just fits within the window, with the peak window boundary marking the

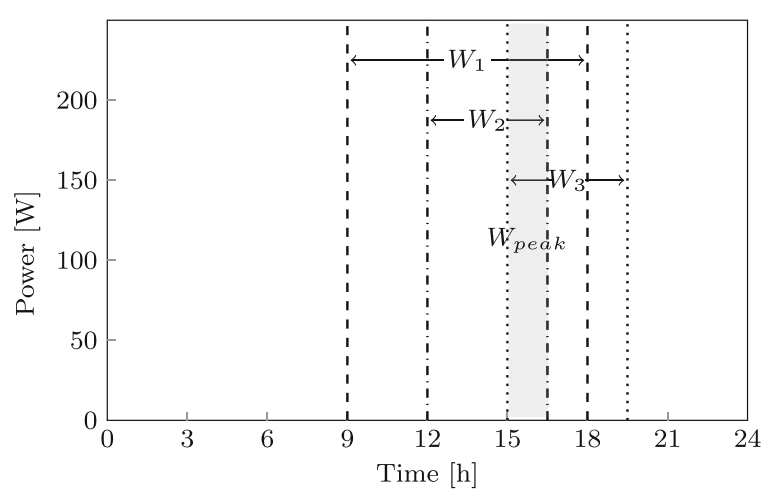

Fig. 4 Concept illustration of peak window (shaded region) as an intersection of 3 different load usage windows 


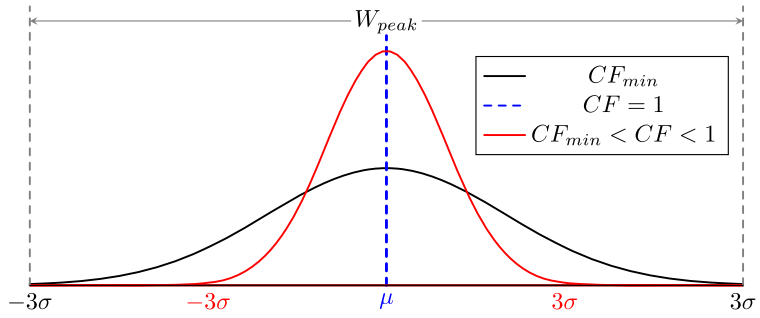

Fig. 5 Normal probability distribution of load occurrence in the peak window

$3 \sigma$ limits for the normal distribution. Maximum coincidence factor of 1 would imply a distribution with $\sigma=0$ and therefore the occurrence guaranteed at the center of the peak window.

Additionally, this is used to derive a relationship between $\mathrm{CF}$ and sigma as shown in Eq. $6 . \mathrm{CF}_{\min }$ is fixed at 0.2 in this study.

$\sigma=\frac{1-\mathrm{CF}}{1-\mathrm{CF}_{\min }} \times \frac{W_{\text {peak }}}{6}$

\section{Randomness and constraints}

As the model stochastically builds a load profile in a bottom-up manner by constructing load usages during the day, randomness was incorporated in the model. There are three main parameters that are quantified randomly withing the usage windows. These are cycle times, starting times within the usage window(s), and the number of instances of load occurrence.

Moreover, the starting time for the specific occurrence in the peak window is handled using a normal distribution and the coincidence factor as explained in the "Peak window and coincidence factor" section. The load profile construction efforts described in this paper have been executed in MATLAB, and the randomness has been achieved with the help of the internal random number generator of MATLAB.

Additionally, there are several constraints that the various parameters are bound by. These are listed as follows.

1. $i \in\left[1, n_{j}\right]$

2. $j \in[1, N]$

3. $n_{j} \in\left[n_{j_{\min }}, n_{j_{\max }}\right]$, where $n_{j_{\min }}$ and $n_{j_{\max }}$ are the lower and upper bounds of the number of instances of load occurrence for load $j$ in a window respectively.
4. $T_{i j} \in\left[T_{j_{\min }}, T_{j_{\max }}\right]$ where $T_{j_{\min }}$ and $T_{j_{\max }}$ are the lower and upper bounds of the cycle times respectively.

5. $\sum_{i=1}^{n_{j}} T_{i j} \leq T_{\mathrm{m}, j}$

6. $t_{i j} \in W_{j} \forall i j$. Additionally, $t_{i j}+T_{i j} \in W_{j}$

These constraints change across the different load categories. The values of each of these constraints for the various loads and different tiers have been captured in Table 3.

\section{Stochastic load profile model}

The stochastic load profile construction methodology is illustrated through the flowchart presented in Fig. 6. The methodology is executed in MATLAB in four distinct phases. They are as described below.

1. Phase I: Stochastic generation In this phase, for every load $j$, the number of instances $n_{j}$ of load occurrence during the day is randomly generated using the random number generator in MATLAB. Then, for each load instance occurrence $i$, a cycle time $T_{i j}$ is randomly generated. The peak window $W_{\text {peak }}$ is also determined in this phase. The various constraints, quantity of loads, rated power, and coincidence factor $(\mathrm{CF})$ are also taken as inputs in this phase.

2. Phase II: Occurrence Distribution The occurrence time instance $t$ of every load instance $i$ is determined randomly in this step. Note that one occurrence is deliberately considered inside the peak window, using normal probability distribution with parameters derived from the coincidence factor, as explained in Eq. 4 in the "Peak window and coincidence factor" section. The occurrence $t_{i}$ occurs inside the allowed window(s) $W$, so that in general $t_{i j} \in W_{j}$. The cycle time $T_{i}$ is added to $t_{i}$. At this time, phase III is executed to validate the cycle time of the load. If valid, then phase II is executed again for the next load instance $i$. If invalid, then the cycle time is constrained according to either of 2 criteria as mentioned in phase III, and then phase II is executed for the next load instance $i$. If $i$ was already the same as $n$, then phase II is implemented for the next load of the same type if the quantity $q>1$. If the functioning window $f$ has been generated for all $q$, then the execution proceeds to the next load $j$. For every execution of phase II, the allowed window 
Fig. 6 Flowchart illustrating the stochastic load profile estimation for one day. The process is repeated for the whole year across every tier

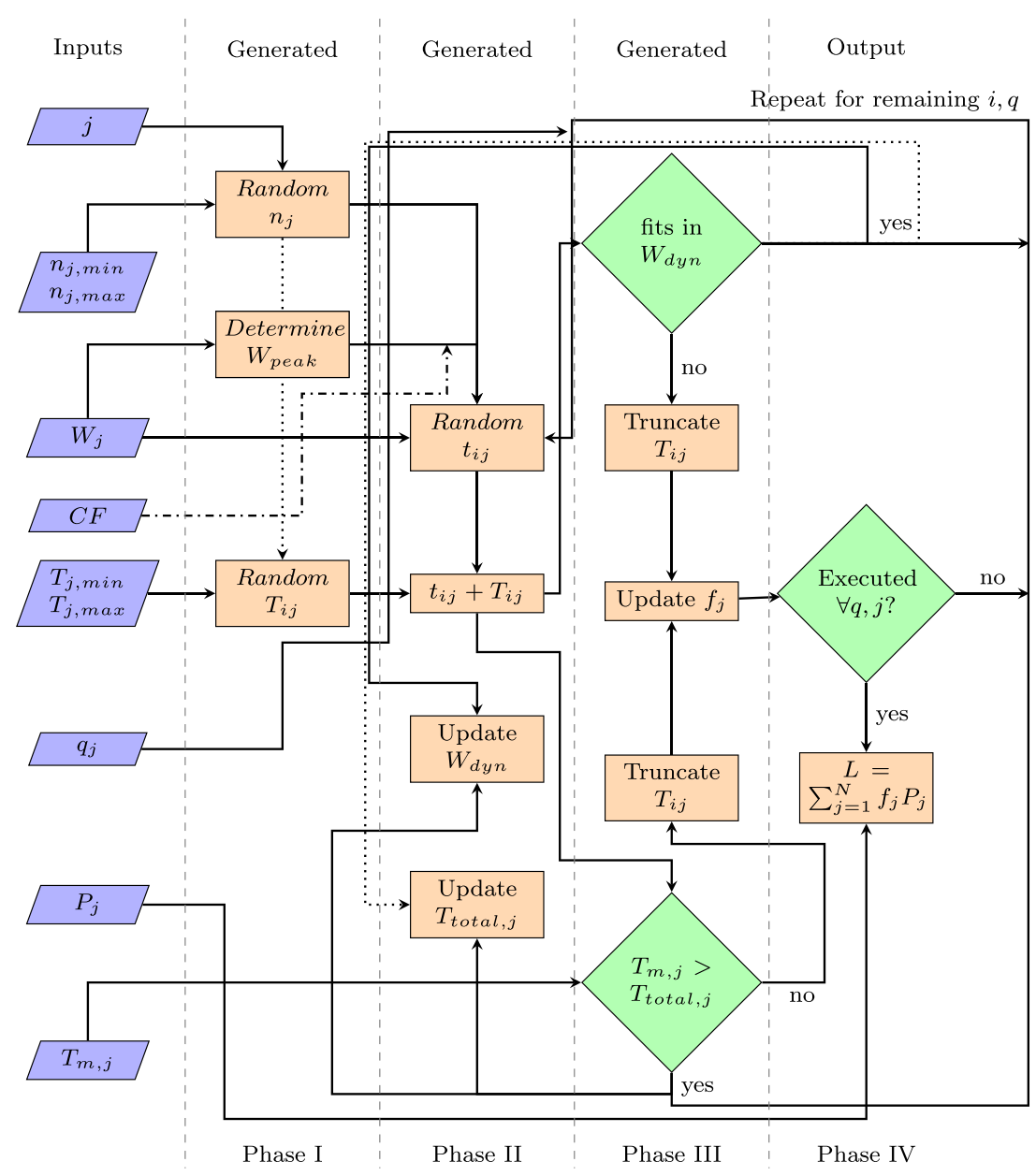

the loads. Finally, the load profile is aggregated taking the quantity $q$ of the loads and the power rating $P$ into account as shown in Eq. 7 .

$L=\sum_{j=1}^{N} f_{j} P_{j}$

where $L$ is the final load profile vector of length 1440 , owing to the 1-min resolution of $f$. The load profile generation is repeated 365 times for a yearly load profile.

The procedure described is valid for the generation of the load profile for $N$ loads within the user group. The same procedure can be followed with different inputs and constraints to obtain the load profiles from various tiers. The reader is referred to Table 3 to peruse the entire list of inputs and constraints as used in this study. 


\section{Assumptions in the methodology}

There are a few careful assumptions in the presented methodology. These are:

1. No occurrence of the load takes place outside the usage window. Therefore, the choice of usage window largely dictates the particular load's contribution in the overall load profile. The usage windows shown in Table 3 have been considered as the typically expected values, which could be made more precise as usage preference data is available from the field.

2. For some of the loads, like laptop, tablet, and mobile phone charging, the loads in these cases specifically denote just the charging of the devices' battery and not the usage of the loads itself.

3. The load power is constant throughout its occurrence and is equal to the rated power. The only exception to this is the refrigerator, as explained below.

It must also be noted that the methodology presented here is strictly for load profile construction, and not for load forecasting.

\section{The case of the refrigerator}

Unlike the rest of the loads, the fridge's energy consumption is rated differently and therefore deserves special treatment. The power consumption behavior of the fridge is not taken to be at rated power at all times. This is because manufacturers often specify two parameters, the rated power and the daily energy consumption under testing conditions.

For example, an off-grid DC-powered fridge is rated at $40 \mathrm{~W}$ with a daily energy consumption of $114 \mathrm{Wh}$ at $32.2^{\circ} \mathrm{C}$ ambient temperature (SunDanzer 2016). The daily energy mentioned translates to a steady consumption of $4.75 \mathrm{~W}$, much lower than the rated power of $40 \mathrm{~W}$. This is because the daily energy only denotes the consumption when the fridge is largely in standby, and otherwise switches on due to self-checks. This neglects the switching on of the fridge due to external events like the door opening and new food addition.

The methodology described in this study assumes the rated standby and self-check consumption without external events. Additionally, the load instances $i$ occurring through the day are considered to be the external events causing the fridge to switch on and consume $40 \mathrm{~W}$ for the cycle times $T_{i}$. Just as the other loads, the number of event instances will be constrained as $i \in[1, n]$ and $n \in\left[n_{\min }, n_{\max }\right]$.

Advantages of the methodology

The load profile construction methodology developed in this study enjoys several advantages, as listed below.

1. Scalability The load profiles constructed in this study were at a household level, given the background of electricity access and the MTF. However, as the methodology is bottom-up, the same method can be used to scale up the scope from household to neighborhood or even village level. The coincidence factor will need to be appropriately changed.

2. Randomness The stochastic nature of the load profiles embodies uncertainty, reflecting human behavior. For example, there is consistency with the usage windows for each load. However, the number of times of load usage and the cycle times are still inconsistent within constraints. This allows for multiple load profile generations within the same set of given input data constraints.

3. Yearly load profile The yearly load profile contains unique daily load profiles. For instance, the load profile constructed for day 1 can be quite different from that of, say, day 200 in a given year. This is a welcome change from the yearly load profiles that are simply the same daily load repeated 365 times. This is helpful in sizing an off-grid system and understanding the system's battery behavior over a larger span of time.

4. Adaptability The procedure described is flexible enough to incorporate more or different appliances in the future or even change the specifications of any load that makes up the load profile. The load profiles can be further customized based on precise demographic inputs and requirements from a specific community through fieldwork, for instance.

5. Ease of system design Due to increasing needs of the off-grid population, SHS designers often need to oversize their systems to enable future growth of consumption. This could be planned better with 
the methodology which helps quantify the energy consumption in the form of load profiles.

\section{Results and discussions}

Based on the inputs described in Table 3 to the methodology described in Fig. 6, different load profiles are obtained for the various tiers of the MTF. For ease of discussion, only the daily load profiles are shown here and discussed.

All the data from the generated load profiles have been made freely accessible at https://doi.org/10.4121/ uuid:c8efa325-87fe-4125-961e-9f2684cd2086.

\section{Stochastic load profiles for MTF}

Figure 7 shows a tier 1 load profile for a representative day from the year-long load profile. As only a handful of loads operate in this case, both the peak power and the energy consumption is the lowest compared to the rest of tiers.

Figure 8 shows a daily tier 2 load profile for a representative day. Similar to tier 1 load profile, the characteristic peak occurs in the evening with moderate consumption during the day.

Figure 9 shows a daily tier 3 load profile for a representative day. An additional base load can be seen in this case due to the fridge. As described earlier, the consumption of the fridge is not modelled based

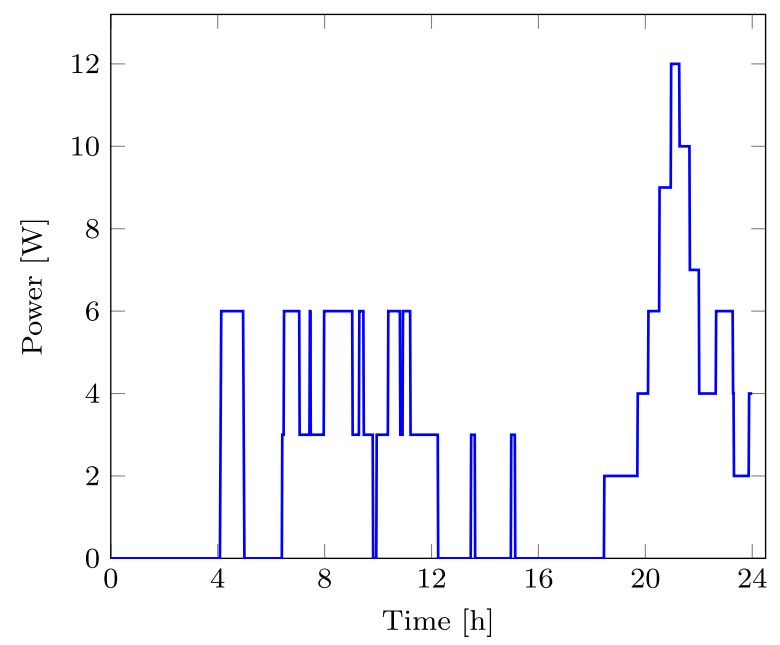

Fig. 7 Load profile of an off-grid household with tier 1 electricity access for a representative day. Total energy consumption for this day is $60 \mathrm{Wh}$ with a peak of $12 \mathrm{~W}$

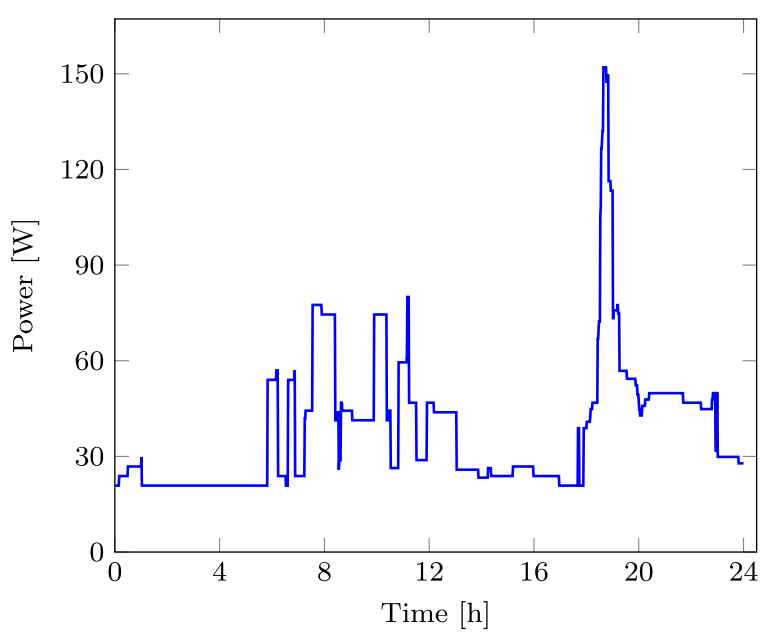

Fig. 8 Load profile of an off-grid household with tier 2 electricity access for a representative day. Total energy consumption for this day is $262 \mathrm{Wh}$ with a peak of around $51 \mathrm{~W}$

on the duty cycle. Instead, a base average consumption is assumed from the manufacturer's data, and the external usage events are modelled.

Figure 10 shows a daily tier 4 load profile for a representative day. Due to the high-power appliances used in this category, the peak power (around $1 \mathrm{~kW}$ ) is much more pronounced.

Figure 11 shows a daily tier 5 load profile for a representative day. As this tier is assumed to contain appliances that support PUE as well, a very high peak of $2.5 \mathrm{~kW}$ can be seen. Moreover, the peaks of all the

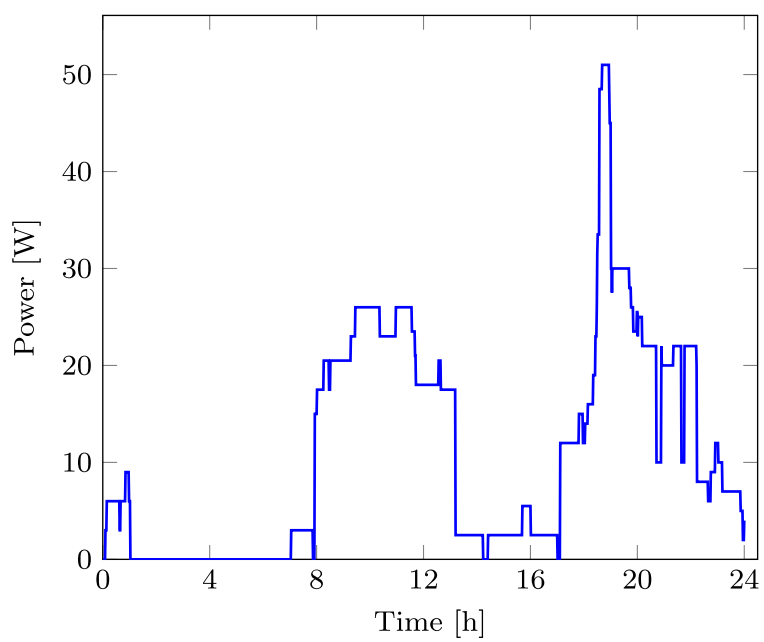

Fig. 9 Load profile of an off-grid household with tier 3 electricity access for a representative day. Total energy consumption for this day is $914 \mathrm{Wh}$ with a peak of around $150 \mathrm{~W}$ 


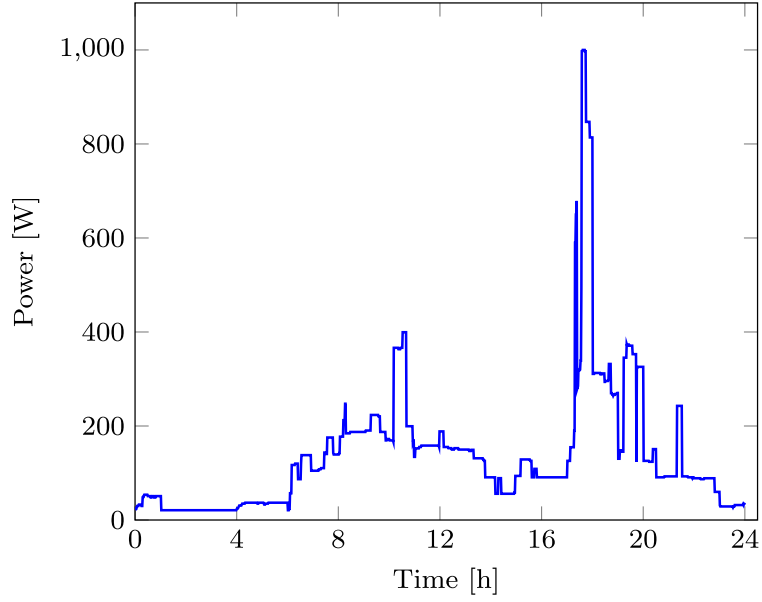

Fig. 10 Load profile of an off-grid household with tier 4 electricity access for a representative day. Total energy consumption for this day is $3.29 \mathrm{kWh}$ with a peak of around $1 \mathrm{~kW}$

load profiles lie in the peak window based on the coincidence factor as explained in the "Peak window and coincidence factor" section.

\section{Load profiles: main parameters}

The main parameters of the load profiles discussed in the "Load profile parameters" section have been captured in Table 5.

Here, $P_{\max }$ is the maximum value attained by $P_{L, \text { Peak }}$ throughout the year, while $P_{\min }$ is the minimum value.

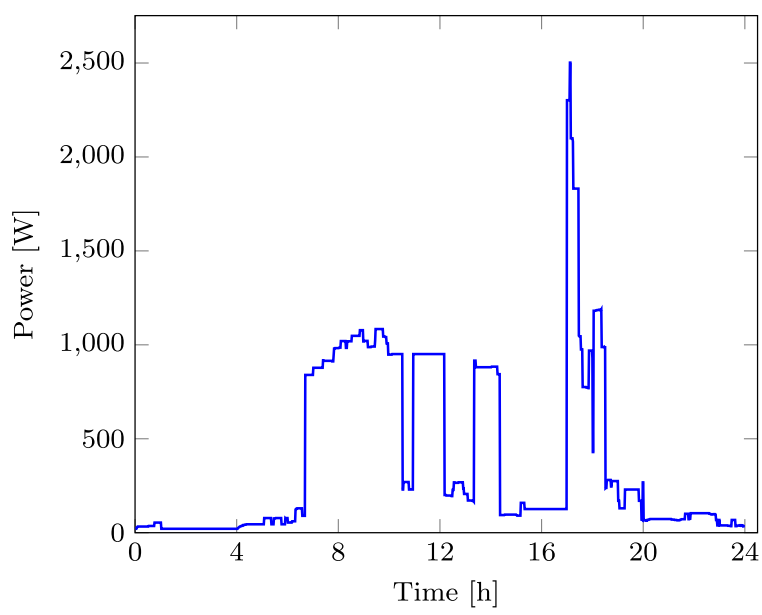

Fig. 11 Load profile of an off-grid household with tier 5 electricity access supporting PUE loads for a representative day. Total energy consumption for this day is $9.34 \mathrm{kWh}$
Table 5 Maximum peak power $P_{\max }$, minimum peak power $P_{\text {min }}$, average daily energy $\overline{E_{\text {daily }}}$ and load factor for the load profiles for each tier based on the 1-year generated load profile

\begin{tabular}{llllll}
\hline & Tier 1 & Tier 2 & Tier 3 & Tier 4 & Tier 5 \\
\hline$P_{\max }(\mathrm{W})$ & 12 & 51 & 154 & 1670 & 3081 \\
$P_{\min }(\mathrm{W})$ & 6 & 35 & 113 & 583 & 1732 \\
$\overline{E_{\text {daily }}}(\mathrm{Wh})$ & 50 & 218 & 981 & 3952 & 9531 \\
Load factor (-) & 0.17 & 0.18 & 0.26 & 0.10 & 0.13 \\
\hline
\end{tabular}

When compared with the energy and power limits mentioned by the MTF (refer Table 1), it can be seen that the constructed load profiles (in terms of $\overline{E_{\text {daily }}}$ and $P_{\max }$ ) conform to these limits. The only exception is tier 3, where the $P_{\max }$ is lower than the minimum limit as mentioned in the MTF. This is because of the super-efficient appliances already available and in use, which impact the overall power consumption. The impact of the efficiency of these appliances is more apparent in tier 3 than the lower tiers. The higher tiers 4 and 5 are still seeing advances being made in terms of dedicated, high-power, efficient, off-grid appliances.

It must be noted that the existing solar lanterns, SHSs or mini-grid solutions only span tiers 1 to 3 in terms of off-grid electrification. There is still a long way to go before most current off-grid communities can reach tier 4 and 5 consumptions. Nonetheless, climbing up the rural electrification ladder is inevitable, and when the expected tier 4 and 5 consumptions are reached, viable energy solutions need to be in place.

The higher tier load profiles can be seen to have lower load factors due to the tall peaks of the high power appliances. This would have severe implications on the battery size and the battery lifetime of stand-alone systems like SHSs if that were to solely satisfy these load profiles.

The values obtained in Table 5 can be tailored based on the kind of loads being used and the corresponding usage restrictions that are captured in Table 3, which is the expected use of this methodology.

Implications on system design

This section outlines the implications of the tier-based load profiles on the system design for the tiers. A standalone solar PV and battery-based (off-grid) energy 
system is considered in a location with around 4.5 equivalent sun hours (ESH), which is usual for most tropical and equatorial regions.

Tier 1 load profile shown in Fig. 7 could be typically satisfied with a 15 to $20 \mathrm{Wp}$ PV module and corresponding battery storage. This is already being done in the field by pico-solar products or smaller SHS designs. The tier 2 load demand shown in Fig. 8 could be typically satisfied with around $50 \mathrm{Wp} \mathrm{PV}$ module and corresponding battery size for a location in the tropical belt, which is what a present-day small SHS can provide. Finding the optimal battery size requirement would need a more detailed analysis based on the year-long load profile and the specific meteorological data.

Tier 3 load profile would need around $250 \mathrm{Wp}$ of $\mathrm{PV}$, which is about the typical size of a contemporary residential solar panel used in the developed world. Only a handful SHS providers currently operate with such PV dimensions when catering to householdlevel, stand-alone, off-grid SHS. Tier 4 load profile would need almost $1 \mathrm{kWp}$ of PV module. A load peak of around $1 \mathrm{~kW}$ (Fig. 10) and overall peak of $1.67 \mathrm{~kW}$ (Table 5) would have implications on the optimal dimensioning of the battery and the power electronics of the system, which needs a dedicated analysis.

Tier 5 load profile shows a load peak of around $2.5 \mathrm{~kW}$ (Fig. 11) and an overall peak of around $3 \mathrm{~kW}$ due to the high-power appliances that enable PUE. A stand-alone system would demand a PV of around $2.5 \mathrm{kWp}$ and corresponding battery and power electronics to match. This shows that supporting the highpower, dedicated, PUE-enabling appliances is going to be an exacting challenge on the size of a standalone system like SHS. Guaranteeing zero loss-of-load events would call for a highly oversized stand-alone system. A microgrid with distributed generation might be a more suited option.

Most importantly, as the household under consideration climbs up the rural electrification ladder, the increase in the appliances owned and therefore energy consumption would also mark a movement up the tiers. Therefore, a stand-alone system design that aims to enable this future growth has to be modular in nature, such that higher energy demand can be met with a modular addition of PV and/or battery. However, modularity alone would still not suffice for enabling consumption at tier 4 and 5 levels with only a stand-alone system. For such high levels of consumption, guaranteeing full power availability is bound to lead to wastage of energy due to oversizing of the system. A central, top-down community microgrid implementation may be the solution, but it is usually not cost-effective, incurs high capital expenditure (CAPEX), and also renders the previous SHS obsolete. Instead, the authors propose the use of modular stand-alone SHS design that could also be interconnected into a bottom-up, organically growing microgrid.

\section{Comparison with field data}

At the time of writing this article, most prevalent SHSs and other off-grid systems deployed at household level were only catering up to tier 2 , or in some cases, tier 3 level electricity access. BBOXX, an SHS provider in Rwanda, East Africa, offers a portfolio of efficient DC appliances along with the SHS. Figure 12 shows a single day load profile of an off-grid SHS from BBOXX capable of powering 3 LED lights $(1.2 \mathrm{~W}$ nominal consumption) and a USB port for charging a mobile phone and a portable radio. The consumption limits would deem this to be a tier 1 load profile. Also shown is a stochastically generated load profile, with different inputs matching those corresponding to the appliances of the SHS in the field.

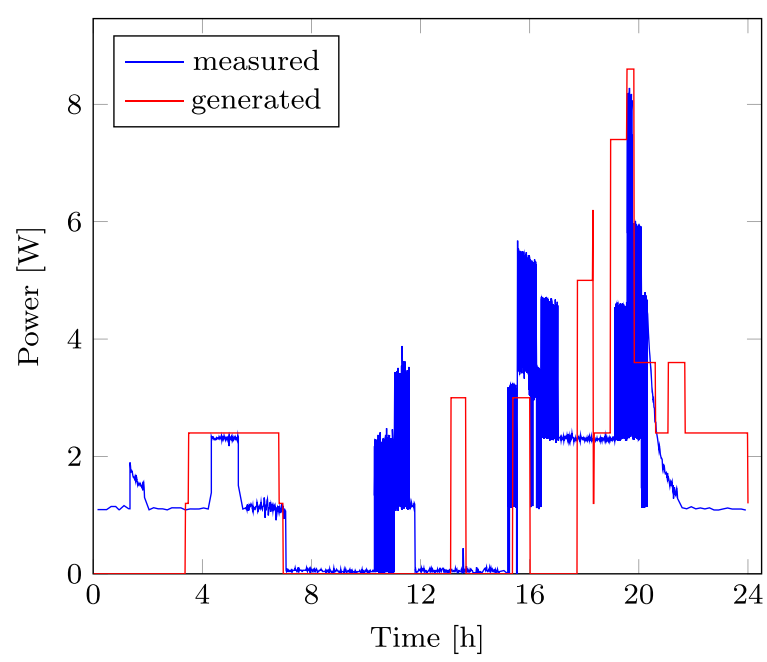

Fig. 12 Comparison of a generated stochastic load profile with the measured load consumption over a single day of a household in Rwanda powered by an SHS from BBOXX 
The generated profile seems to match the measured one closely, especially with respect to the peak load in the peak window in the evening. The total daily energy of the measured load profile is $35.7 \mathrm{Wh}$, while that of the generated one is $34.7 \mathrm{Wh}$, representing a $2.9 \%$ error. Furthermore, the load factor of the measured load profile is 0.18 while that of the generated load profile is 0.17 . A much greater match can naturally be achieved if needed by adjusting the operational constraints. However, the comparison here is to merely exemplify the usefulness of the described methodology.

\section{Conclusions}

This paper described a bottom-up, stochastic load profile construction methodology to quantify the energy needs for the various tiers of the MTF. The loads were entirely composed of dedicated, off-grid, and in some cases the so-called super-efficient appliances. Advantages like scalability, adaptability, and randomness of the proposed methodology were identified. A method for incorporating coincidence factor as a design input for the methodology was also introduced. Several stochastic load profiles were created using the described methodology, and their impact on standalone system design for the different load profiles has been underlined. The impact of appliances enabling productive use of energy was also investigated through a tier 5 load profile construction. The utility of this methodology can be greatly augmented with the availability of local data and complemented with targeted surveys per target community/region.

The load profile construction methodology described in this paper is expected to greatly help various offgrid electrical system designers in constructing load profiles and customizing energy solutions to cater to the growing energy needs of the un(der)-electrified population.

\section{Recommendations and future work}

The methodology described assumes rated power consumption of these DC appliances throughout the usage of the appliance. In reality, some appliances may consume differently based on their usage. For now, only the fridge has been treated as a special case. Other examples could include the starting power consumption of an appliance, or the varying power consumption of an LCD TV depending on the screen illumination, which can be quite different from the rated power. In the absence of actual power consumption profiles of these up-and-coming DC appliances, the current load profile construction methodology is considered to be sufficient. More light will be hopefully shed in the future by the real-time data gathered from SHSs in the field. Finally, the most natural progression of this work will be towards the sizing of the off-grid systems like SHSs for the various electricity access tiers based on these load profiles, where the aforehand knowledge of the load profiles can greatly help in the optimal sizing of these systems.

Acknowledgements The authors are grateful to Ashley Grealish from BBOXX for providing the 1-day usage data from their SHS in Rwanda. Special thanks to Frans Pansier for the discussions on power consumption of the fridge. The authors also acknowledge Natalie Kretzschmar, Thomas den Heeten, Victor Vega, and Daniel Reyes.

Funding information This work is supported by a fellowship from the Delft Global Initiative of Delft University of Technology.

\section{Compliance with Ethical Standards}

Conflict of interest The authors declare that they have no conflict of interest.

Open Access This article is distributed under the terms of the Creative Commons Attribution 4.0 International License (http:// creativecommons.org/licenses/by/4.0/), which permits unrestricted use, distribution, and reproduction in any medium, provided you give appropriate credit to the original author(s) and the source, provide a link to the Creative Commons license, and indicate if changes were made.

\section{Appendix}

Table 6 lists down the loads used in the study. The model number and basic specifications of the loads are mentioned, along with the corresponding source wherever applicable. 
Table 6 List of appliances used for constructing the load profile

\begin{tabular}{|c|c|c|}
\hline Loads & Sample model number(s) & Source \\
\hline LED lighting & SL $1220 C F 120$ & Phocos (2016) \\
\hline Mobile phone & Samsung Guru Plus & Samsung (2016) \\
\hline Radio & Fosera, FS106 & GIZ (2016) \\
\hline Fan & $\begin{array}{l}\text { ONergy 10” BOX FAN, } \\
\text { FS91, ONergy 16” PEDESTAL } \\
\text { FAN, FS92, Ceiling Fan ME-103-DC }\end{array}$ & GIZ (2016), Global LEAP (2016b) \\
\hline TV & $\begin{array}{l}\text { Fosera DC TV 15.6” } 12 \mathrm{~V} \text {, } \\
\text { D.light design 18.5" LE185N91C, } \\
\text { Mobisol 24" MSDV2310MY-308C1 }\end{array}$ & Global LEAP (2016b) \\
\hline Fridge & $\begin{array}{l}\text { Solar Chill, FS52, } \\
\text { Sundanzer DCR 50, DCR } 165\end{array}$ & SunDanzer (2016), GIZ (2016) \\
\hline Tablet & HP Pro Tablet 10 EE G1 & HP (2016) \\
\hline Kettle & Solar DC Kettle SE520, FS65 & GIZ (2016) \\
\hline Laptop & Generic Laptop & - \\
\hline Rice cooker & SR-3NA-S & Panasonic (2016) \\
\hline Clothes iron & $\begin{array}{l}\text { Solar DC Power Iron Dry/ Spray } \\
\text { style-12V SL100S, FS192 }\end{array}$ & GIZ (2016) \\
\hline Washing machine & Washing Machine CERAD, FS127 & GIZ (2016) \\
\hline Air cooler & DC Solar Air Conditioner, DC4812VRF & Hotspot Energy (2016) \\
\hline Power tools & $\begin{array}{l}\text { Bosch 18V Lithium Ion 4-Tool Combo } \\
\text { Kit (CLPK414-181), FS84 }\end{array}$ & GIZ (2016) \\
\hline Grinders/millers & Grain Mill Solar Milling, FS32 & GIZ (2016) \\
\hline Sewing machine & Sewing Machine CERAD, FS73 & GIZ (2016) \\
\hline Water pump & Solar Surface Slow Pump Dankoff, FS10 & GIZ (2016) \\
\hline
\end{tabular}

\section{References}

Bhatia, M., \& Angelou, N. (2015). Beyond connection, energy access redefined. The World Bank. [Online]. Available: https://openknowledge.worldbank.org/bitstream/handle/ 10986/24368/Beyond0connect0d000technical0report.pdf? sequence $=1 \&$ is Allowed $=y$.

Bhattacharyya, S.C., \& Timilsina, G.R. (2010). Modelling energy demand of developing countries: are the specific features adequately captured? Energy Policy, 38(4), 19791990. [Online]. Available: https://doi.org/10.1016/j.enpol. 2009.11.079.

Blodgett, C., Dauenhauer, P., Louie, H., Kickham, L. (2017). Accuracy of energy-use surveys in predicting rural mini-grid user consumption. Energy for Sustainable Development, 41, 88-105. [Online]. Available: https://doi.org/10.1016/j.esd.2017.08.002.

Boait, P., Advani, V., Gammon, R. (2015). Estimation of demand diversity and daily demand profile for off-grid electrification in developing countries. Energy for Sustainable Development, 29, 135-141.

GIZ (2016). Photovoltaics for productive use applicationsa catalogue of DC-appliances. Deutsche Gesellschaft für Internationale Zusammenarbeit (GIZ) GmbH.
Global LEAP (2015). Off-grid appliance market survey. Tech. Rep. Washington, DC: Global LEAP Lighting and Energy Access Partnership, Tech. rep.

Global LEAP (2016a). The state of the off-grid appliance market. Tech. rep. Washington, DC: Global LEAP Lighting and Energy Access Partnership, Tech. Rep. [Online]. Available: http://www.cleanenergyministerial.org/Portals/ 2/pdfs/Global_LEAP_The_State_of_the_Global_Off-Grid_ Appliance_Market.pdf.

Global LEAP (2016b). Global leap awards-2016 buyer's guide for outstanding off-grid fans and televisions. Tech. Rep. Washington, DC: Global LEAP Lighting and Energy Access Partnership, Tech. Rep. [Online]. Available http://globalleap. org/s/Global-LEAP-Awards-Winners-Finalists.pdf.

Global Off-Grid Lighting Association (2018). Global off-grid solar market report-semi-annual sales and impact data. GOGLA, Lighting Global and Berenschot, Tech. Rep.

Gustavsson, M. (2007). With time comes increased loads: an analysis of solar home system use in Lundazi, Zambia. Renewable Energy, 32(5), 796-813.

H. Energy (2016). Datasheet. Solar/DC Air Conditioner DC4812VRF.

Hartvigsson, E., \& Ahlgren, E.O. (2018). Comparison of load profiles in a mini-grid: assessment of performance metrics 
using measured and interview-based data. Energy for Sustainable Development, 43, 186-195. [Online]. Available: https://doi.org/10.1016/j.esd.2018.01.009.

Heeten, T.D., Narayan, N., Diehl, J.C., Verschelling, J., Silvester, S., Popovic-Gerber, J., Bauer, P., Zeman, M. (2017). Understanding the present and the future electricity needs: consequences for design of future solar home systems for off-grid rural electrification. In 2017 international conference on the domestic use of energy (DUE) (pp. 8-15).

Hirmer, S., \& Guthrie, P. (2017). The benefits of energy appliances in the off-grid energy sector based on seven o ff -grid initiatives in rural Uganda. Renewable and Sustainable Energy Reviews, 79, 924-934. [Online]. Available: https://doi.org/10.1016/j.rser.2017.05.152.

HP (2016). Datasheet. HP Pro Tablet EE G1.

IEA (2017). Energy Access Outlook 2017-from poverty to prosperity, 1st edn. Organization for Economic Cooperation and Development, International Energy Agency.

Kooijman-van Dijk, A.L. (2008). The power to produce: the role of energy in poverty reduction through small scale Enterprises in the Indian Himalayas. University of Twente.

Louie, H., \& Dauenhauer, P. (2016). Effects of load estimation error on small-scale off-grid photovoltaic system design, cost and reliability. Energy for Sustainable Development, 34, 30-43. [Online]. Available: https://doi.org/10.1016/j.esd.2016.08.002.

Mandelli, S., Merlo, M., Colombo, E. (2016). Novel procedure to formulate load profiles for off-grid rural areas. Energy for Sustainable Development, 31, 130-142. [Online]. Available: https://doi.org/10.1016/j.esd.2016.01.005.

Narayan, N., Papakosta, T., Vega-Garita, V., Popovic-Gerber, J., Bauer, P., Zeman, M. (2017). A simple methodology for estimating battery lifetimes in solar home system design. In 2017 IEEE AFRICON (pp. 1195-1201).

Nuno, J., António, M., Ribeiro, L. (2012). A new clustering algorithm for load profiling based on billing data. Electric Power Systems Research, 82(1), 27-33. [Online]. Available: http://www.sciencedirect.com/science/ article/pii/S0378779611002033.

Paatero, J.V., \& Lund, P.D. (2006). A model for generating household electricity load profiles. International Journal of Energy Research, 30(5), 273-290.

Palit, D., \& Bandyopadhyay, K.R. (2016). Rural electricity access in South Asia: is grid extension the remedy? A critical review. Renewable and Sustainable Energy Reviews, 60, 1505-1515. [Online]. Available: https://doi.org/10.1016/j.rser.2016.03.034.

Panasonic (2016). Datasheet. Automatic Rice cooker SR-3NA-5.

Park, W.Y., \& Phadke, A.A. (2017). Adoption of energyefficient televisions for expanded off-grid electricity service. Development Engineering, 2, 107-113. [Online]. Available: http://www.sciencedirect.com/science/article/ pii/S2352728516300057.

Phadke, A.A., Jacobson, A., Park, W.Y., Lee, G.R., Alstone, P., Khare, A. (2015). Powering a home with just 25 watts of solar pv. super-efficient appliances can enable expanded off-grid energy service using small solar power systems. Lawrence Berkeley National Laboratory (LBNL), Berkeley. Tech. Rep.
Phocos (2016). Datasheet. Led Light SL 1220CF 120.

Räsänen, T., Voukantsis, D., Niska, H., Karatzas, K., Kolehmainen, M. (2010). Data-based method for creating electricity use load profiles using large amount of customer-specific hourly measured electricity use data. Applied Energy, 87, 3538-3545.

REN21 (2017). Renewables 2017 global status report. Paris, REN21 Secretariat.

Riva, F., Ahlborg, H., Hartvigsson, E., Pachauri, S., Colombo, E. (2018). Electricity access and rural development: review of complex socio-economic dynamics and casual diagrams for more appropriate energy modelling. Energy for Sustainable Development, 43, 203-223. [Online]. Available: https://doi.org/10.1016/j.esd.2018.02.003.

Riva, F., Tognollo, A., Gardumi, F., Colombo, E. (2017). Long-term energy planning and demand forecast in rural areas of developing countries: classification of case studies and insights for a modelling perspective. Energy Strategy Reviews, 20, 71-89. [Online]. Available: https://doi.org/10.1016/j.esr.2018.02.006.

Sajjad, I.A., Chicco, G., Napoli, R. (2014). A probabilistic approach to study the load variations in aggregated residential load patterns. In 2014 power systems computation conference (pp. 1-7).

Samsung (2016). Datasheet. Mobile phone Guru Plus.

Smets, A.H., Jäger, K., Isabella, O., Van Swaaij, R., Zeman, M. (2016). Solar energy, the physics and engineering of photovoltaic conversion technologies and systems. Cambridge: UIT.

SunDanzer (2016). Datasheet. DCR50 DC powered refrigerator.

Swan, L.G., \& Ugursal, V.I. (2009). Modeling of end-use energy consumption in the residential sector: a review of modeling techniques. Renewable and Sustainable Energy Reviews, 13(8), 1819-1835.

Tenenbaum, B., Greacen, C., Siyambalapitiya, T., Knuckles, J. (2014). From the bottom up: how small power producers and mini-grids can deliver electrification and renewable energy in Africa. Washington DC: World Bank Publications.

Treado, S. (2015). The effect of electric load profiles on the performance of off-grid residential hybrid renewable energy systems. Energies, 8(10), 11120-11138.

Troja, B. (2016). A quantitative and qualitative analysis of the super-efficient equipment program subsidy in India. Energy Efficiency, 9(6), 1385-1404. [Online]. Available: https://doi.org/10.1007/s12053-016-9429-8.

Tsekouras, G., Kotoulas, P., Tsirekis, C., Dialynas, E., Hatziargyriou, N. (2008). A pattern recognition methodology for evaluation of load profiles and typical days of large electricity customers. Electric Power Systems Research, 78(9), 1494-1510. [Online]. Available: http://www.sciencedirect. com/science/article/pii/S0378779608000278.

United Nations (2017). [Online]. Available: http://www.un.org/ sustainabledevelopment/sustainable-development-goals/.

Wolfram, C., Shelef, O., Gertler, P. (2012). How will energy demand develop in the developing world? J. Econ. Perspect., 26(1), 119-138. [Online]. Available: http://pubs. aeaweb.org/doi/10.1257/jep.26.1.119. 